Article

\title{
Program Coherence and Integration of School- and Work-Based Learning in the Icelandic Dual Vocational Education and Training (VET) System
}

\author{
Elsa Eiríksdóttir ${ }^{\mathbb{D}}$ \\ School of Education, University of Iceland, 105 Reykjavík, Iceland; elsae@hi.is
}

Received: 21 August 2020; Accepted: 28 October 2020; Published: 2 November 2020

check for updates

\begin{abstract}
This study examines how recently graduated journeymen, vocational teachers, and workplace trainers view the integration between learning at school and at work in a dual vocational education and training (VET) system, and how these views might be influenced by the duration and the sequencing of school- and work-based learning periods. Research indicates that effective implementation of the dual VET system is contingent upon successful integration of learning experience at the two venues. Recent graduates, workplace trainers, and teachers in all 51 certified trades answered an electronic questionnaire (667 participants, response rate $24 \%$ ). Factor analysis of responses to 22 statements resulted in the identification of five factors. Findings show that the learning venues were parallel rather than integrated. Communication and collaboration between teachers and workplace trainers were limited and recent graduates, in particular, did not experience the program as a coherent whole. The results also showed important variations in the perspectives of the three groups of participants. The duration of the workplace learning period was not found to be associated with perceptions of program integration. Some limited effects of sequencing were found, but no clear pattern emerged. This study adds to knowledge on learning and integration, and indicates possible ways of improving program coherence and integration in a dual VET system.
\end{abstract}

Keywords: vocational education and training; upper secondary schools; work-based learning; dual VET system

\section{Introduction}

In the dual system of vocational education and training (VET), part of the program takes place at school and part at work. Research has shown that learning at these two venues can be complementary in helping students develop the necessary competencies, e.g., [1-8]. However, the success of a dual-system program appears to depend on its coherence and the integration of school- and work-based learning [4,5,8-11]. Additionally, models of work-based learning, such as the connective model of work experience [2] and model of integrative pedagogy [12], have emphasized the importance of integrating learning from the two venues in the dual system. Successfully integrating learning at school and work appears essential for effective implementation of a dual VET system.

Prior research on the Icelandic dual VET system has indicated a lack of coherence and integration in some fields $[13,14]$. When interviewed, newly graduated journeymen, teachers at VET schools, and workplace trainers in four different VET fields all described a system in which school and work operated in parallel rather than as an integrated whole. The aim of the current study is to investigate whether this is generally the case in the Icelandic VET system and to specifically look at the different aspects of integration as perceived by those who have studied and taught within the system. In addition, it also examines if other characteristics of the organization of the dual system influence 
these perceptions; notably, the duration of the period devoted to work-based learning, and sequencing of periods at the workplace and in school during the course of the program.

\section{Integrating Learning at School and at Work}

The term "dual system of VET" (sometimes also referred to as alternance training) [15], is used to refer to an educational program in which work experience forms part of the curriculum, such as those in Germany, Switzerland, Austria, Denmark, and Iceland. In such a program, work-based learning is an integral part of the overall program. The student has the status of an apprentice (under a training contract), the employer assumes responsibility for providing the training, and the apprentice receives wages $[15,16]$.

In the dual system, the two learning venues provide different, but complementary, learning experiences $[4,7,17]$. Learning at school is formal and provides opportunities for reflection, theoretical insights, peer interaction, and making mistakes. Learning experiences are structured and clearly organized around specific topics, knowledge, or skills. In contrast, learning at workplaces is informal and provides opportunities for learning experiences not easily acquired at school, such as customer service and keeping up with developments in a field [4,17]. The workplace is an ideal setting for learning about the experience of working in the trade, and also provides the context for legitimate participation in the field and developing vocational identity $[1,4,7]$. The opportunities for learning experience at school and the workplace are bound by the goals of each venue. Education is the main goal of schools; creating optimal situations for learning and training is therefore at the forefront. The workplace is not oriented towards learning in the same way and the learning opportunities are bound within what is available within the normal operations of the workplace [1,7]. Due to the different goals, learning opportunities, and experiences at each venue, the transfer of learning and training between the two is an important issue $[4,18]$. In particular, the coherence and integration of the learning experiences gained at each is critical $[1,5,9,19]$ because a disconnect between the learning experiences at the two venues can be a problem $[7,8]$.

Models of work-based learning such as the connective model of work experience $[2,20]$ and the model of integrative pedagogy [12,19] have emphasized the importance of integrating learning from the two venues in the dual system. Both models highlight forging the connection between the practical (associated with workplaces) and the theoretical (associated with schools) at both venues by reflecting on practical experiences in terms of theory and theoretical knowledge in practice. This connection between theoretical and practical learning experiences should accordingly also be formalized in VET program curricula. The connective model puts emphasis on communication and collaboration between those organizing learning at each venue [2], whereas the integrative pedagogy model emphasizes the integration through the use of learning tasks and pedagogical tools such as reflections and discussions [12]. This shows that integration of learning experiences at the two venues can have different aspects and depend on, for example, communications between the two venues or the pedagogical practices within each.

Research on learning at school and the workplace has shown that cooperation and communication between workplace trainers and teachers at school, and deliberate reflection on learning experiences at the two venues, contribute to the transfer of training in a dual system [5-7,21]. In a culture of cooperation, it becomes possible for both teachers and trainers to build a shared understanding and create learning experiences for students that build upon what they have been learning and doing in each venue. It has also been pointed out that cooperation between schools and workplaces needs a reliable framework and suitable forms to guarantee the quality of vocational education [8] because "the cooperation of learning venues takes place in practice and on the spot" (p. 16).

Successful transfer of training between school and work also depends upon teachers and trainers creating the necessary conditions for students to be able to integrate learning experiences from each, for example, by adopting educational practices associated with the other learning venue [10,21-24]. A key issue is how to support students in critical reflection on their learning experiences across 
venues $[17,18]$. Teachers and trainers need to assist students in making a connection between different types of knowledge accessed at school and in the workplace, because this does not happen automatically [7]. Virtanen et al. [5] investigated influences on students' work-based learning outcomes, and found that better integration between school learning and work-based learning was associated with better self-reported learning outcomes. In particular, pedagogical practices supporting learning, such as goal-setting and discussions, were found to play a significant part. Other researchers have also found that pedagogic practices that assist students in reflecting on their learning experiences at work, and connecting what is discussed at school to authentic situations, helps learning [7,21].

Overall, research on learning at school and work has indicated that the success of a dual system depends in part on the degree to which school- and work-based learning are integrated $[4,5,7,9,10]$. Billett [9] provides an outline of what such integration might entail in terms of a socio-personal account. In this account, it is not only the physical and social aspects of each venue that are important for shaping learning, but also how the students engage with and create meaning from their experiences at each venue. Integration is seen as the results of how students frame their experiences and construct meaning, and they need guidance and assistance to do this. Therefore, the organization of curricula and pedagogical practices play a role, in particular, the duration and sequencing of the work-based periods within the vocational program.

\section{Dual System Characteristics: Duration and Sequencing}

There are reasons to believe that both variations in duration and sequencing may influence the integration of learning experiences at work and school [4,9]. Spending the majority of the time learning in a workplace compared to a school should lead to different educational outcomes. In the most extreme cases, this determines which - the school or the workplace — students see as the main learning venue and which provides more marginal learning experiences to be integrated into what has been learned [14]. This can create difficulties when it comes to guaranteeing communication and collaboration between schools and workplaces, and ensuring that students have the opportunity for reflection and connecting learning acquired at each venue. The level of collaboration and communication between teachers and trainers may easily be influenced by the amount of time spent at-and by inference, the importance attributed to-each venue. Sequencing can also be seen as important for integration. There is a trade-off between having an early or late work-based learning period: an early one can help give students a sense of what working in the trade entails, but at the same time, they might not have enough knowledge and skills to participate in, or understand, the complexities of the tasks and situations confronted there $[9,14]$. A later work-based period can be valuable as the students should have acquired the necessary knowledge and skills to participate in, and understand, the work, but it might be too late to provide them with the necessary experience regarding what the work entails and the context for learning $[4,14,25]$. The principle of "gradual release" addresses a similar issue in recommending that theoretical knowledge should not be "front-loaded" in a program but sequenced iteratively with practical experience, thereby assisting learners in overcoming gaps between theory and practice in the course of the program [26,27]. In addition, Billett [25] suggests that "educational interventions prior to vocational education students' engaging in work placements are important. Then, once they have completed those experiences, interventions to assist their integration into these students' nascent occupational understandings, procedures and values will also be valuable" (p. 28). Therefore, both pre- and post-placement educational interventions are important for assisting students in integration learning experiences from school and work, and sequencing should, among other things, determine whether there are opportunities to introduce these beneficial interventions.

\section{The Dual VET System in Iceland}

In Iceland, most VET programs are at the upper secondary level. At the age of 16, after having completed compulsory education, the majority of young people enroll in upper secondary school. However, most enter the so-called academic tracks and graduate with a matriculation (university 
entrance) exam and only about one-third of the enrolled students at upper secondary level are in VET programs [28]. There are over 100 different VET programs available and they take an average of 3-4 years to complete [29]. Here, the focus is on the certified trades where a journeyman's certificate is required by legislation to work in a field [30], such as hairdressing, book-binding, tailoring, carpentry, and electrical work. The VET system in Iceland is generally organized as a dual system, one of alternating duality where students spend relatively long phases full-time either at school or in the workplace [8]. At school, the vocational teachers organize and teach courses, but at workplaces, certified masters in the trade are in charge of the training. Students are responsible for securing a training contract with a workplace and organizing their workplace and school periods in concordance with the curriculum. After completing both the school-based and the work-based parts of the program, the student can take the journeyman's exam, which is an independent exam held by industry stakeholders.

In all of the certified trades, work-based learning consists of a predetermined number of weeks defined in the program curriculum, where students have a company training contract and are paid for their work. An analysis of 31 curricula of the certified trades revealed considerable variation in terms of both duration and sequencing [14]. Duration of work-based learning ranged from 24 to 126 weeks, or $16 \%$ to $74 \%$, of the program as a whole. This means that in some cases, the program is mainly school-based whereas in others, it is mostly based at work. Regarding sequencing, four main patterns determining where the program should begin and end were found across the curricula: (1) begin at school-end at school (School-School, 8 trades), (2) begin at school-end at the workplace (School-Workplace, 12 trades), (3) begin at school-end at either the school or the workplace (School-Either, 7 trades), (4) begin either at school or the workplace-end at school (Either-School, 4 trades). This means that in some trades, students begin their studies at school and end them at school, completing the work-based learning along the way, whereas in other trades, the students begin at school and conclude the program with work-based learning. This level of variability within a single VET system is rare [31] and provides an opportunity to investigate the possible influence of these variables in the dual system. That is, the variations in the sequencing and duration of work-based learning in the certified trades in Iceland provides an opportunity for studying how these features of the dual VET system can influence perceptions of program coherence and integration of learning at both venues.

\section{Aims and Research Questions}

The aim of the study is to investigate how the integration of two learning venues in the certified trades in Iceland is perceived by recently graduated journeymen, vocational teachers, and workplace trainers, and how the different implementation of the dual system, in terms of duration and sequencing, might influence these perceptions. These three groups were chosen as they have the most insight into the experience of studying and teaching in the certified trades, and how integration of learning experiences across the two venues progresses. Integration, as discussed above, involves communication and collaboration of those in charge of teaching at each venue and creating the learning opportunities through different pedagogical tools. Integration also involves the students themselves creating meaning from their learning experiences gained at school and work. Therefore, understanding the perspectives of students, vocational teachers, and workplace trainers in a dual system is essential. Recently graduated journeymen were chosen rather than current students because they have experiences with the program as a whole, including the workplace periods.

The views of journeymen, workplace trainers, and vocational teachers in the certified trades in Iceland were obtained through an online questionnaire and analyzed to answer the following research questions: (1) What do the participants' answers say about the different facets of integrating learning in a dual system? (2) Do the views of the three groups of participants differ in respect to the perceived integration of the two venues of learning? (3) Does the duration of the work-based learning or the sequencing pattern influence the perceived integration of learning at school and the workplace? 


\section{Materials and Methods}

\subsection{Participants}

Participants were recently graduated journeymen (graduating in the past five years), workplace trainers (who had taken apprentices in the past five years), and vocational teachers in all certified trades in Iceland. The questionnaire was sent to recently graduated journeymen rather than students as the interest was in their whole experience of studying in the certified trades, including completing both work-based learning and the journeyman's exam. Due to the differences between the programs, it would be difficult to interpret answers from students still studying, for example, in cases in which work-based learning is placed at the end of the program. Furthermore, it was important to have the views of those who had recent experiences with studying the certified trades and therefore, only those graduating within the past two to five years were recruited.

E-mail addresses for 2175 journeymen, 722 trainers, and 263 teachers were obtained $(N=3160)$, representing $68 \%$ of the journeymen population, $43 \%$ of the trainer population, and $100 \%$ of the vocational teacher population. E-mail addresses of the journeymen and the trainers were obtained from the training centers overseeing workplace contracts; those of the teachers were obtained from VET school websites. Of the e-mail accounts for journeymen and trainers, 332 proved to be closed (it was not clear whether individual e-mail addresses were those of journeymen or trainers) and thus, the final number of participants was 2828 .

A total of 667 participants answered the questionnaire (24\% overall response rate). The response rate for the teachers was $46 \%(n=121), 26 \%$ for the workplace trainers $(n=187)$, and $15 \%$ for the journeymen $(n=319)$. A likely reason for the low response rate for the journeymen and trainers is that many of the e-mail accounts were no longer in use, even if they had not been closed. It has to be noted that because of the low response rate for the journeymen and trainers, and because the questionnaire was sent to the prospective participants, there is no way to know if the respondents were, as a whole, representative of these groups or if a self-selection or non-response bias might skew the results. However, the respondents appear to adequately represent the expected frequency for trade, gender, and age in the population. The respondents represented all of the main trade categories (e.g., building industry, vehicle and transport, service trades) and the percentage of participants within each trade category and individual trades belonging to the category (e.g., carpentry, plumbing, painters) was found to be representative of the population. The majority of respondents (73\%) were males (23\% were women, and $4 \%$ did not answer) and this distribution is also found in the population in these trades [28]. The percentage of women was similar for the three groups of participants: $25 \%$ of journeymen were women, $25 \%$ of teachers, and $20 \%$ of trainers. The majority of journeymen (75\%) were between 20 and 40 years of age, whereas the majority of teachers $(76 \%)$ were over 50 years old and two-thirds of the trainers (62\%) were between 40 and 60 years old.

\subsection{The Questionnaire}

The questionnaire covered various topics related to studying in a dual system, i.e., on the integration of the periods at school and work, competencies developed at school and work, and identity development. The questionnaire was developed based on results from prior interviews with journeymen, teachers, and trainers [13,14], and from Virtanen et al. [5], who constructed questions to assess the integration between school- and work-based learning. These were based on the connective model of work experience by Guile and Griffiths [2,20], and the integrative pedagogy model by Tynjälä [19].

The current focus is on questions on the integration of school- and work-based parts of the program, communication, collaboration, and characteristics of the two learning environments: a total of 22 statements (see Appendix A for a list of the statements). Participants indicated the degree to which they agreed or disagreed with each statement on a 4-point Likert scale (strongly disagree, disagree, 
agree, strongly agree) or they could choose "not applicable" (NA). In the results, the percentages of those either agreeing or disagreeing were aggregated for simplicity.

Only two of the three groups (journeymen, trainers, or teachers) answered 7 of the 22 statements (see Appendix A), because the excluded group did not have detailed knowledge about the issue at hand. For example, recent journeymen did not rate the statement "At school/at the workplace, we prepare students specifically for the journeyman's exam", teachers did not respond to the statement "During work-based learning, students have to apply knowledge acquired at school", and workplace trainers did not respond to the statement "At school we discuss situations that might come up at the workplace".

\subsection{Procedure}

After the questionnaire had been developed, the institutions responsible for registering apprenticeship contracts and journeyman's exams were contacted to obtain e-mails of journeymen and trainers. To maintain privacy, the researchers received only a list of e-mails and no further information about the participants. E-mails of teachers were obtained from the web pages of the upper secondary schools offering VET programs, but in each case, the headmaster of the school was notified that the questionnaire would be sent to the teachers.

After the questionnaire was sent out, the participants received five reminders over the course of three months before data collection was closed. As the researchers only had access to e-mails and not to other identifying information, it was not possible to specifically follow up with those who had not answered the questionnaire with more targeted methods, such as phone calls.

\subsection{Statistical Methods}

An exploratory factor analysis (with varimax rotation) was used to investigate the underlying pattern of responses in terms of the factors extracted. For a factor analysis with 22 variables, a sample size of at least 220 is required (with a sample size of 300 considered good) [32], and in all cases but two, the sample size was larger (see Appendix A). In addition, the Kaiser-Mayer-Olkin measure indicated good sampling adequacy for the analysis $(K M O=0.825)$. A factor loading cut-off of 0.30 was used, based on the sample size, and missing values were replaced with the mean to minimize the effect of missing data. The resulting five factors with eigenvalues greater than 1 were used to organize the results and the items loading on each factor were then used to create new dependent variables for each factor, or factor scores (i.e., regression factor scores) [33]. These factor scores were then used to investigate differences among participant groups, duration, and sequencing. An ANOVA (with Tukey's post-hoc tests) was used to investigate if the factor scores depended on the participant group. A multiple regression was used to determine if duration of work-based learning (in the range of 24-126 weeks) and sequencing based on where the program was set to begin and end (School-School, School-Workplace, School-Either and Either-Workplace) predicted the factor scores. The categorical predictor, sequencing, was dummy coded and School-School represented the comparison group. The variables were entered as predictors into five separate analyses, one for each factor score. The assumptions for multiple regression were checked: For two of the five factor scores, an analysis of standard residuals indicated outliers ( 5 cases in factor score 1 and 2 cases in factor score 5 ) and these were removed. Multicollinearity was not a concern as all tolerance scores were larger than 0.1 and variance inflation factors were around 1. Independence of observations (i.e., residuals) was assessed with the Durbin-Watson statistic and the values were in the range of 1.74 to 2.07 for all five factor scores, indicating no autocorrelation. Histograms of standardized residuals showed that the errors were approximately normally distributed and the normal P-P plots of standardized residuals showed points approximately on the diagonal line. Assumptions of linearity and homoscedasticity were evaluated based on the scatterplot of standardized residuals and these indicated that the assumptions were met. In addition, a Loess curve was fitted to the graphs, and in all five cases, was roughly linear around zero. 


\section{Results}

The factor analysis of the 22 items returned five factors with an eigenvalue over Kaiser's criterion of 1 , explaining $41.5 \%$ of the overall variance. Cronbach's alpha values ranged from 0.72 to 0.84 , indicating good internal consistency or reliability for the five factors [32]. Table 1 shows the statements' loading on each factor. Two items did not load sufficiently on any factor above the minimum cut-off (a factor loading of 0.3), "At the school we prepare the students specifically for the workplace" and "There should be more emphasis on the work-based learning at school", and both were therefore excluded from further analysis.

Table 1. The five factors resulting from a rotated (varimax) factor analysis and the statements' loading on each.

\begin{tabular}{|c|c|c|c|c|c|}
\hline \multirow{2}{*}{ Factors and Statements } & \multicolumn{5}{|c|}{ Factor Loading } \\
\hline & 1 & 2 & 3 & 4 & 5 \\
\hline \multicolumn{6}{|c|}{ 1. Quality and usefulness of work-based learning (explains $11.83 \%$ of the variance) } \\
\hline $\begin{array}{l}\text { 1.1. The work-based learning prepares students well for the } \\
\text { journeyman's exam }\end{array}$ & 0.807 & & & & \\
\hline $\begin{array}{l}\text { 1.2. The work-based learning serves students well after the } \\
\text { journeyman's exam }\end{array}$ & 0.752 & & & & \\
\hline $\begin{array}{l}\text { 1.3. The training received in the workplace serves students well } \\
\text { at school }\end{array}$ & 0.659 & & & & \\
\hline 1.4. The workplace is up-to-date on developments in the trade & 0.658 & & & & \\
\hline 1.5. The workplace offers experiences in most relevant parts of the job & 0.643 & & & & \\
\hline \multicolumn{6}{|c|}{ 2. The school keeps up with innovations in the trade (explains $8.22 \%$ of the variance) } \\
\hline $\begin{array}{l}\text { 2.1. Innovative changes in the trade are integrated into the } \\
\text { school curriculum }\end{array}$ & & 0.823 & & & \\
\hline 2.2. The school is up-to-date on developments in the trade & & 0.820 & & & \\
\hline \multicolumn{6}{|l|}{ 3. Program coherence and collaboration (explains $7.27 \%$ of the variance) } \\
\hline 3.1. The periods at school and work create a coherent whole & & & 0.791 & & \\
\hline 3.2. Students work on school assignments at the workplace & & & 0.555 & & \\
\hline 3.3. There is good collaboration between the school and the workplace & & & 0.505 & 0.404 & \\
\hline $\begin{array}{l}\text { 3.4. There is a clear connection between what is taught at school and } \\
\text { tasks in the workplace }\end{array}$ & & & 0.363 & 0.332 & \\
\hline \multicolumn{6}{|l|}{ 4. Communications and information flow (explains $7.23 \%$ of the variance) } \\
\hline 4.1. Teachers and workplace trainers are in regular contact & & & & 0.702 & \\
\hline 4.2. Teachers know what students do during the work-based learning & & & & 0.582 & \\
\hline 4.3. Workplace trainers know what students do at school & & & & 0.513 & \\
\hline 4.4. Teachers and trainers meet regularly to discuss students' progress & & & & 0.310 & \\
\hline \multicolumn{6}{|c|}{ 5. Relevance and usefulness of school-based learning (explains $6.94 \%$ of the variance) } \\
\hline $\begin{array}{l}\text { 5.1. Assignments at school are clearly related to the work done in } \\
\text { the trade }\end{array}$ & & 0.399 & & & 0.622 \\
\hline $\begin{array}{l}\text { 5.2. At school we discuss situations that might come up in the } \\
\text { workplace }\end{array}$ & & & & & 0.474 \\
\hline 5.3. Students visit workplaces as a part of the school program & & & & & 0.416 \\
\hline 5.4. The school prepares students well for the journeyman's exam & & 0.326 & & & 0.385 \\
\hline $\begin{array}{l}\text { 5.5. During work-based learning students apply knowledge acquired } \\
\text { at school }\end{array}$ & & & & & 0.318 \\
\hline
\end{tabular}


Factors' scores were calculated for each factor. The factor scores are standardized and indicate the degree to which the participants' rating on the statements' loading on the factor compare to the mean of the sample as a whole. A value close to zero indicates a rating close to the sample average, whereas a negative value indicates a rating lower than the sample average and a positive value indicates a higher rating. Table 2 shows the means and standard deviations for each factor score and each independent variable. In the following sections, the results for each factor are discussed in more detail.

Table 2. Means and standard deviations (in parentheses) for all five factor scores for each independent variable. The overall factor score for the sample is standardized with $M=0$ and $S D=1$, and the scores for each subgroup represent a comparison to this mean. Note that for explanation purposes, the duration variable is categorized into short, medium, and long duration although this categorization is not used in the analysis.

\begin{tabular}{lccccc}
\hline \multicolumn{1}{c}{ Variable } & $\begin{array}{c}\text { Factor } \\
\text { Score \#1 }\end{array}$ & $\begin{array}{c}\text { Factor } \\
\text { Score \#2 }\end{array}$ & $\begin{array}{c}\text { Factor } \\
\text { Score \#3 }\end{array}$ & $\begin{array}{c}\text { Factor } \\
\text { Score \#4 }\end{array}$ & $\begin{array}{c}\text { Factor } \\
\text { Score \#5 }\end{array}$ \\
\hline Sequencing & & & & & \\
$\quad$ School-School & $-0.02(0.89)$ & $0.07(0.80)$ & $0.11(0.90)$ & $-0.02(0.81)$ & $0.03(0.69)$ \\
$\quad$ School-Workplace & $0.13(0.79)$ & $-0.02(0.93)$ & $-0.07(0.88)$ & $0.03(0.85)$ & $0.03(0.73)$ \\
$\quad$ School-Either & $0.02(0.92)$ & $-0.02(0.95)$ & $-0.02(0.78)$ & $-0.13(0.77)$ & $-0.07(0.78)$ \\
$\quad$ Either-School & $-0.09(0.67)$ & $0.00(0.90)$ & $0.08(0.86)$ & $0.43(0.91)$ & $-0.11(0.67)$ \\
Duration & & & & & \\
$\quad$ Short: 24-48 weeks & $0.04(0.86)$ & $0.10(0.88)$ & $-0.09(0.78)$ & $-0.03(0.81)$ & $-0.06(0.81)$ \\
$\quad$ Medium: 60-80 weeks & $-0.01(0.90)$ & $-0.12(0.91)$ & $0.11(0.90)$ & $0.01(0.83)$ & $0.08(0.70)$ \\
$\quad$ Long: 96-126 weeks & $0.13(0.75)$ & $0.04(0.91)$ & $-0.06(0.88)$ & $0.12(0.79)$ & $0.01(0.64)$ \\
Participant group & & & & & \\
$\quad$ Journeymen & $0.06(0.88)$ & $-0.018(0.93)$ & $-0.25(0.77)$ & $-0.08(0.90)$ & $-0.07(0.85)$ \\
$\quad$ Teachers & $-0.26(0.80)$ & $0.32(0.81)$ & $0.09(0.84)$ & $0.09(0.83)$ & $0.39(0.65)$ \\
$\quad$ Trainers & $0.17(0.85)$ & $-0.18(0.85)$ & $0.37(0.83)$ & $0.07(0.62)$ & $-0.11(0.51)$ \\
\hline
\end{tabular}

\subsection{Quality and Usefulness of Work-Based Learning}

The first factor consisted of five statements all centering on the quality and usefulness of work-based learning. As can be seen in Figure 1, the majority of each group (range of 69-94\%) agreed with each of the five statements, reflecting general satisfaction with the quality and usefulness of work-based learning. This was especially true for the trainers. A notable exception is that half of the teachers disagreed with the statement that the workplace offers experience in most relevant parts of the job, which raises the question of whether the teachers have an overview of the trade in mind, whereas the trainers are more likely to answer from the perspective of their own specialization. Another exception is that only about $60 \%$ of students believed that the training received in the workplace served them well at school, which suggests that they had a harder time seeing the connection between what they do in the workplace and what they learn at school than teachers and trainers might realize.

When comparing the factor scores on quality and usefulness of work-based learning for the three groups of participants, the teachers were significantly less positive $(F(2,585)=9.13, M S E=6.71, p$ $\left.<0.001, \eta^{2}=0.03\right)$ in comparison to the journeymen $(p<0.05 ; 95 \%$ CI $[-0.53,-0.09])$ and trainers $(p<0.001 ; 95 \% \mathrm{CI}[-0.67,-0.19])$, showing that the trainers and journeymen rated the quality and usefulness of work-based learning generally higher than teachers (see Table 2).

Duration of the work-based period and sequencing were not found to be significant predictors of ratings of quality and usefulness of work-based learning (see Table 3 ). 


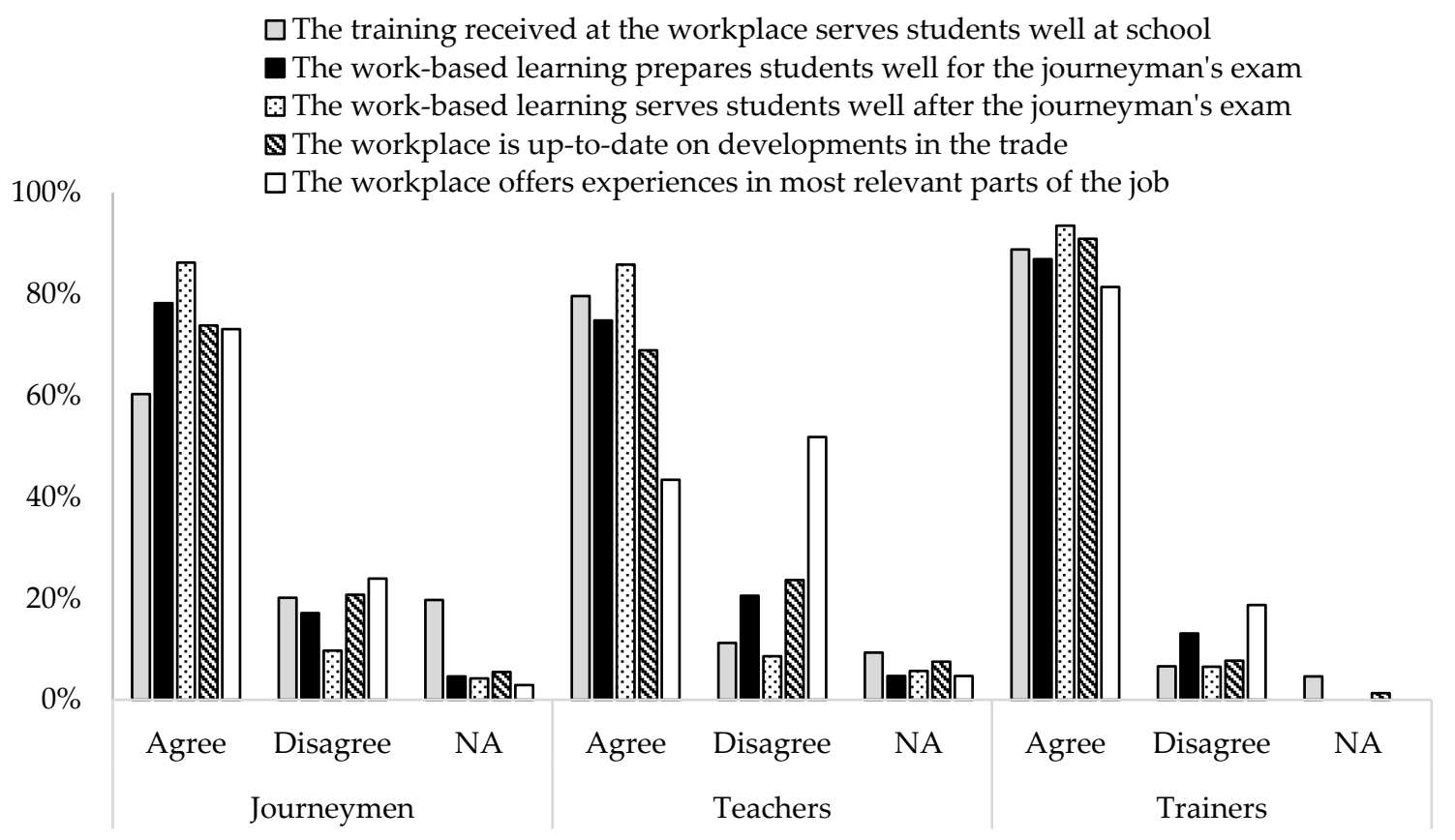

Figure 1. Statements' loading on factor \#1: Quality and usefulness of work-based learning. The figure shows the percentage of each group of participants who agreed (strongly agreed and agreed combined) or disagreed (strongly disagreed and disagreed combined) with each statement, or said the statement was not applicable (NA).

Table 3. Prediction of factor score \#1: Quality and usefulness of work-based learning, from duration and sequencing (dummy coded).

\begin{tabular}{lcccccc}
\hline \multicolumn{1}{c}{ Effect } & \multirow{2}{*}{ Estimate } & \multirow{2}{*}{ SE } & \multirow{2}{*}{$\boldsymbol{\beta}$} & \multicolumn{2}{c}{$\mathbf{9 5 \%}$ CI } & \multirow{2}{*}{$\boldsymbol{p}$} \\
\cline { 5 - 6 } & & & & LL & UL & \\
\hline Duration of workplace learning period & 0.001 & 0.001 & 0.034 & -0.002 & 0.004 & 0.432 \\
Sequencing: School-Workplace & 0.158 & 0.091 & 0.082 & -0.022 & 0.337 & 0.084 \\
Sequencing: School-Either & 0.056 & 0.091 & 0.029 & -0.123 & 0.234 & 0.541 \\
Sequencing: Either-School & -0.092 & 0.161 & -0.025 & -0.410 & 0.225 & 0.568 \\
\hline
\end{tabular}

Note. $N=584$. $\mathrm{CI}=$ confidence interval; $\mathrm{LL}=$ lower limit; $\mathrm{UL}=$ upper limit.

\subsection{The School Keeps up with Innovations in the Trade}

The second factor consisted of only two statements concerning whether the school kept up with innovations in the trade. Teachers were more likely to agree with the two statements than both journeymen and trainers (see Figure 2), reflecting a different sense of the pace and level of innovation in the trade and specifically whether the school kept up with it or not.

A significant difference was found among the three participant groups $(F(2,590)=11.91, M S E=8.91$, $p<0.001, \eta^{2}=0.04$ ) and Tukey's post-hoc test showed that the teachers had significantly higher scores than both journeymen $(p<0.001 ; 95 \%$ CI $[0.11,0.56])$ and trainers $(p<0.001 ; 95 \% \mathrm{CI}[0.25,0.75])$. Thus, teachers were more likely to believe that the schools kept up with innovations in the trade than were the trainers and journeymen (see Table 2).

Neither duration of the work-based period nor sequencing were found to be significant predictors of ratings of how well the school kept up with innovations in the field (see Table 4). 


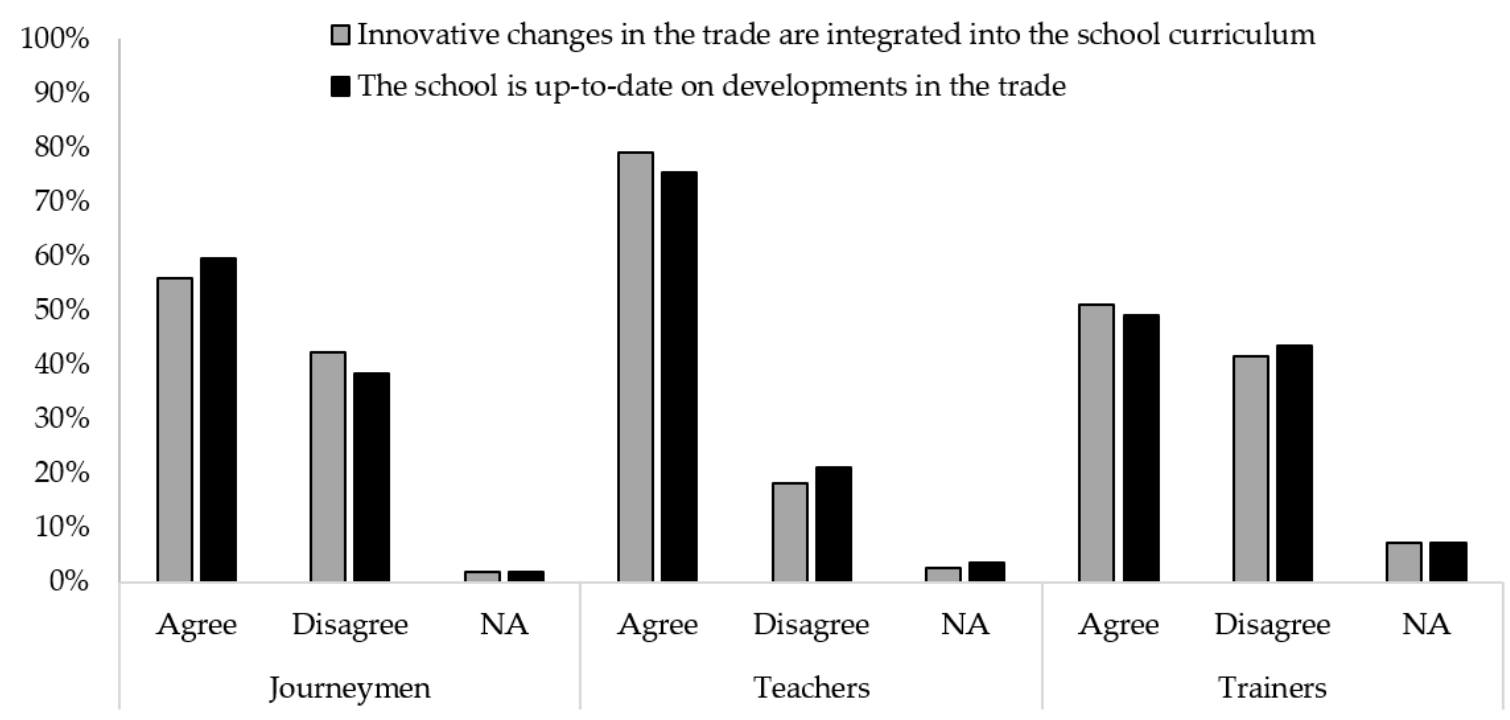

Figure 2. Statements' loading on factor \#2: The school keeps up with innovations in the trade. The figure shows the percentage of each group of participants who agreed (strongly agreed and agreed combined) or disagreed (strongly disagreed and disagreed combined) with each statement, or said the statement was not applicable (NA).

Table 4. Prediction of factor score \#2: The school keeps up with innovations in the trade, from duration and sequencing (dummy coded).

\begin{tabular}{lcccccc}
\hline \multicolumn{1}{c}{ Effect } & \multirow{2}{*}{ Estimate } & SE & $\boldsymbol{*}$ & \multicolumn{2}{c}{$\mathbf{9 5 \% \text { CI }}$} & \multirow{2}{*}{$\boldsymbol{p}$} \\
\cline { 5 - 6 } & & & & $\mathbf{L L}$ & $\mathbf{U L}$ & \\
\hline Duration of workplace learning period & -0.003 & 0.002 & -0.077 & -0.006 & 0.000 & 0.075 \\
Sequencing: School-Workplace & -0.071 & 0.094 & -0.036 & -0.255 & 0.113 & 0.448 \\
Sequencing: School-Either & -0.097 & 0.093 & -0.050 & -0.279 & 0.086 & 0.298 \\
Sequencing: Either-School & 0.018 & 0.166 & -0.005 & -0.309 & 0.345 & 0.914 \\
\hline
\end{tabular}

Note. $N=589$. $\mathrm{CI}=$ confidence interval; $\mathrm{LL}=$ lower limit; $\mathrm{UL}=$ upper limit.

\subsection{Program Coherence and Collaboration}

The third factor consisted of four statements concerning the coherence of the program as a whole and collaboration between the school and the workplace. As can be seen in Figure 3, the journeymen tended to disagree with the statements, indicating that they generally did not see clear program coherence and collaboration. A notable exception is that about $40 \%$ of journeymen agreed that the assignments at schools were clearly related to the work done in the trade. The opinions of the teachers and trainers were more evenly split, indicating that they saw a more coherent program than the journeymen. Overall, these results suggest that programs in the certified trades did not create a coherent whole and that there was a lack of collaboration between the school and the workplace.

A significant difference was found between the three participant groups $(F(2,590)=34.278$; $\left.M S E=22.179, p<0.001, \eta^{2}=0.10\right)$ and Tukey's post-hoc test showed a significant difference among all three groups. The journeymen had significantly lower scores than both the teachers $(p<0.001$; $95 \% \mathrm{CI}[-0.56,-0.14])$ and the trainers $(p<0.001 ; 95 \% \mathrm{CI}[-0.80,-0.44])$, showing that the journeymen found the program to be less coherent and saw less evidence of collaboration between the school and the workplace than did the teachers and the trainers (see Table 2). The teachers also had significantly lower scores than the trainers $(p<0.001 ; 95 \% \mathrm{CI}[-0.51,-0.06])$ and therefore rated the program as less coherent, and collaboration as less evident than the trainers. 
Neither duration of the work-based period nor sequencing were found to be significant predictors of ratings of how well the school kept up with innovations in the field (see Table 5).

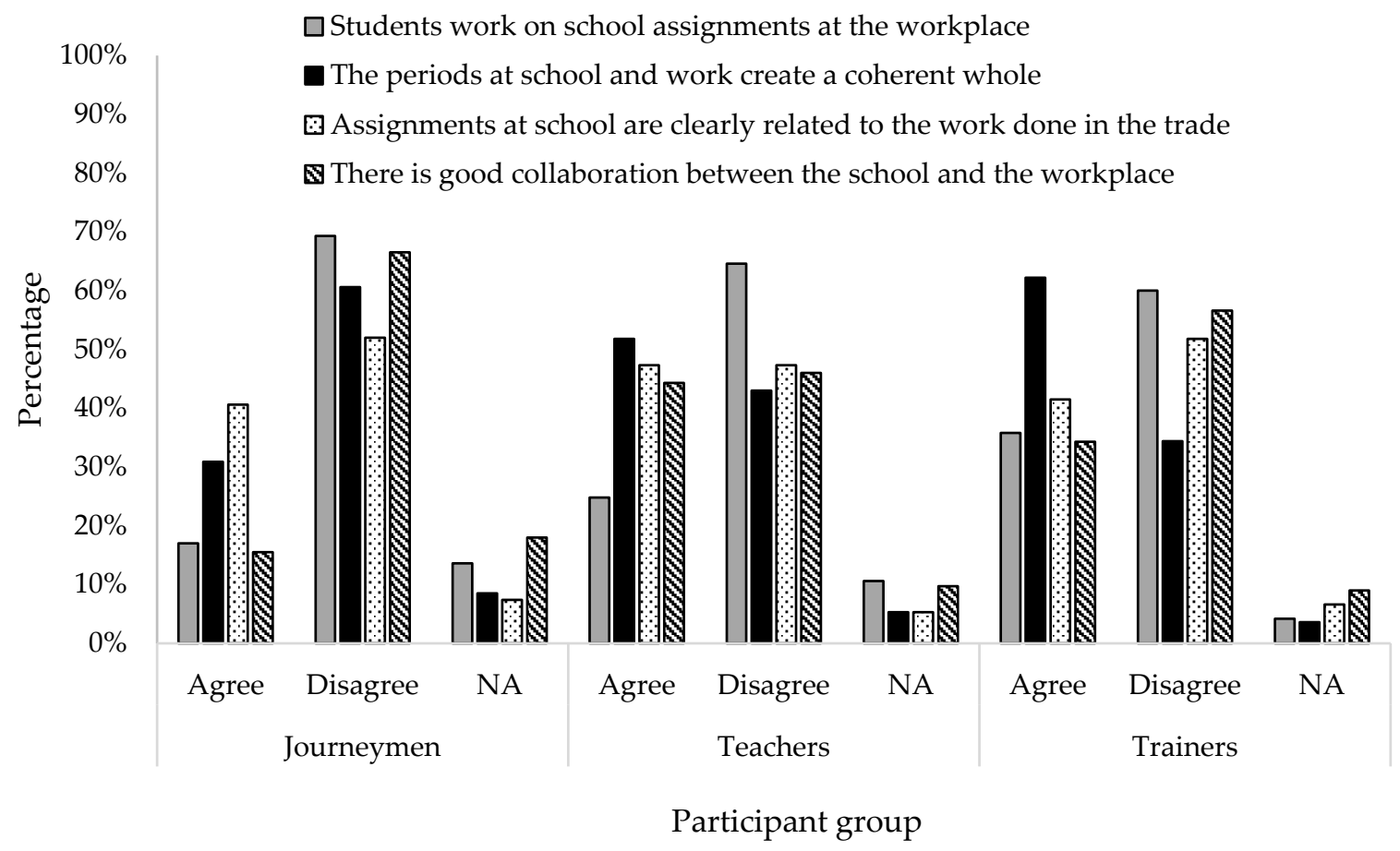

Figure 3. Statements' loading on factor \#3: Program coherence and collaboration. The figure shows the percentage of each group of participants who agreed (strongly agreed and agreed combined) or disagreed (strongly disagreed and disagreed combined) with each statement, or said the statement was not applicable (NA).

Table 5. Prediction of factor score \#3: Program coherence and collaboration, from duration and sequencing (dummy coded).

\begin{tabular}{lcccccc}
\hline \multicolumn{1}{c}{ Effect } & \multirow{2}{*}{ Estimate } & \multirow{2}{*}{ SE } & $\boldsymbol{\beta}$ & \multicolumn{2}{c}{$\mathbf{9 5 \% \text { CI }}$} & \multirow{2}{*}{$\boldsymbol{p}$} \\
\cline { 5 - 6 } & & & & $\mathbf{L L}$ & $\mathbf{U L}$ & \\
\hline Duration of workplace learning period & 0.002 & 0.001 & 0.049 & -0.001 & 0.004 & 0.259 \\
Sequencing: School-Workplace & -0.114 & 0.089 & -0.060 & -0.288 & 0.061 & 0.200 \\
Sequencing: School-Either & -0.050 & 0.088 & -0.027 & -0.223 & 0.122 & 0.567 \\
Sequencing: Either-School & -0.006 & 0.158 & -0.002 & -0.316 & 0.303 & 0.967 \\
\hline
\end{tabular}

Note. $N=589$. $\mathrm{CI}=$ confidence interval; $\mathrm{LL}=$ lower limit; $\mathrm{UL}=$ upper limit.

\subsection{Communications and Information Flow}

The fourth factor consisted of four statements concerning communications and information flow between the school and the workplace. It is notable that for all three groups of participants, the majority (64-71\%) disagreed with the statement that teachers and trainers were in regular contact, and the majority of both teachers and trainers $(71-82 \%)$ disagreed with the statement that they met regularly to discuss students' progress (see Figure 4). Less than half of the journeymen believed that the teachers and trainers knew what the students did at the other learning site, and only about half of the trainers said they knew what the students did at school, while the majority of the teachers said they knew what the students did during the work-based learning period. These results show a distinct lack of communication between those supervising the two parts of the program. 


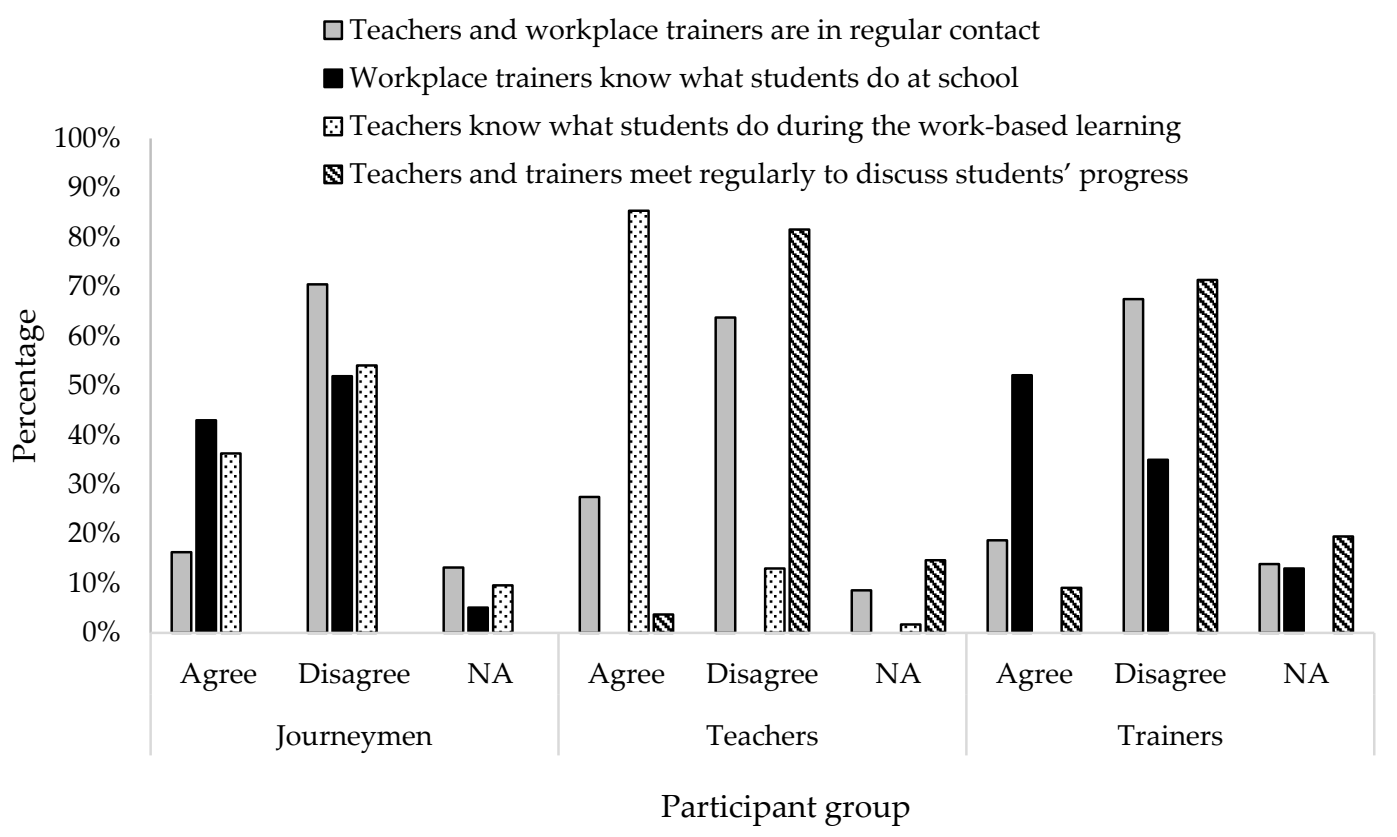

Figure 4. Statements' loading on factor \#4: Communication and information flow. The figure shows the percentage of each group of participants who agreed (strongly agreed and agreed combined) or disagreed (strongly disagreed and disagreed combined) with each statement, or said the statement was not applicable (NA). Note that not all groups evaluated all four statements (see Appendix A).

No difference was found among the three participant groups, indicating an agreement on the lack of communication and information flow $(p>0.05$; see Table 2). Duration of the work-based period did not predict how the participants rated coherence and collaboration between the school and the workplace (see Table 6). However, sequencing was found to explain a significant amount of the variance in the factor score $\left(F(4,584)=3.69, p<0.05, R^{2}=0.03\right)$. The analysis shows that belonging to a trade with an Either-School sequencing pattern significantly predicted a higher score in comparison to belonging to a School-School sequencing pattern (see Table 6). It seems that in the trades belonging to this group, there is a better culture of communication and information flow between the school and the workplace.

Table 6. Prediction of factor score \#4: Communication and information flow, from duration and sequencing (dummy coded).

\begin{tabular}{|c|c|c|c|c|c|c|}
\hline \multirow{2}{*}{ Effect } & \multirow{2}{*}{ Estimate } & \multirow{2}{*}{ SE } & \multirow{2}{*}{$\beta$} & \multicolumn{2}{|c|}{$95 \% \mathrm{CI}$} & \multirow{2}{*}{$p$} \\
\hline & & & & LL & UL & \\
\hline Duration of workplace learning period & 0.001 & 0.001 & 0.023 & -0.002 & 0.003 & 0.598 \\
\hline Sequencing: School-Workplace & 0.016 & 0.085 & 0.009 & -0.151 & 0.183 & 0.850 \\
\hline Sequencing: School-Either & -0.135 & 0.084 & -0.076 & -0.301 & 0.030 & 0.108 \\
\hline Sequencing: Either-School & 0.398 & 0.151 & 0.115 & 0.101 & 0.694 & 0.009 * \\
\hline
\end{tabular}

Note. $N=589 . \mathrm{CI}=$ confidence interval; $\mathrm{LL}=$ lower limit; $\mathrm{UL}=$ upper limit. ${ }^{*} p<0.05$.

\subsection{Relevance and Usefulness of School-Based Learning}

The fifth factor consisted of five statements involving the relevance and usefulness of school-based learning. However, only the journeymen evaluated every statement; the teachers evaluated four, and the trainers only three (see Figure 5). In general, there is a high level of agreement with the statements by all three groups (especially the teachers), indicating that participants considered the school both relevant and useful. The exception is the statement, "There is a clear connection between 
what is taught at school and tasks at the workplace", which about $40 \%$ of journeymen and $45 \%$ of trainers disagreed with (compared to only $10 \%$ of teachers), suggesting a degree of disconnect between how the teachers saw the relevance of what they taught at school and, in contrast, how the journeymen and trainers evaluated this. This might be attributable, for example, to developments in the field, where tasks in the workplace had changed compared with what teachers were familiar with.

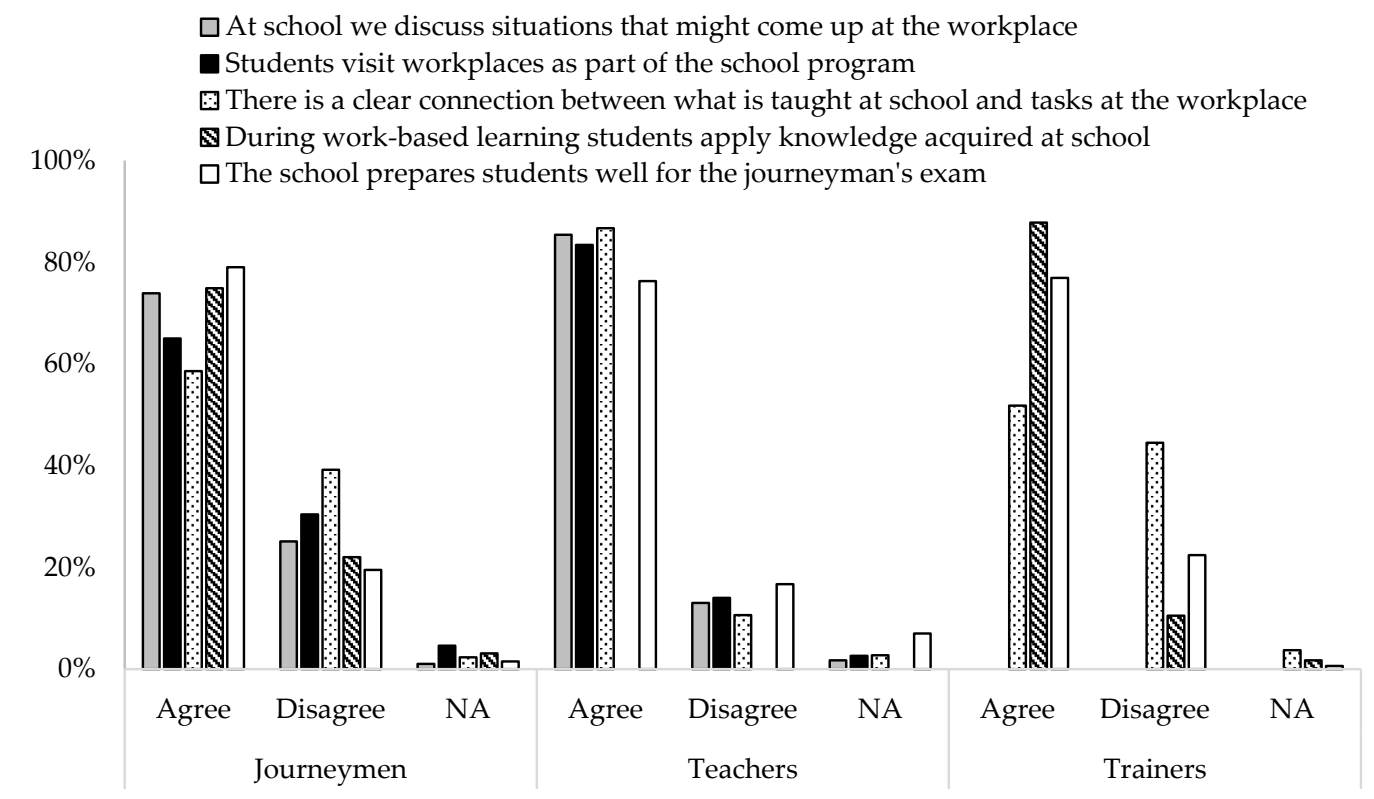

Figure 5. Statements' loading on factor \#5: Relevance and usefulness of school. The figure shows the percentage of each group of participants who agreed (strongly agreed and agreed combined) or disagreed (strongly disagreed and disagreed combined) with each statement, or said the statement was not applicable (NA). Note that not all groups evaluated all four statements (see Appendix A).

Even if the three groups rated a different number of statements, the factor scores are standardized and allow comparison. A significant difference was found between the three participant groups $\left(F(2,588)=19.967 ; M S E=10.507, p<0.001, \eta^{2}=0.06\right)$. Tukey's post-hoc test showed a significant difference between the teachers and the journeymen on one hand $(p<0.001 ; 95 \% \mathrm{CI}[0.27,0.64])$ and the trainers on the other $(p<0.001 ; 95 \%$ CI $[0.30,0.71])$. These results show that, in general, the teachers rated the relevance and usefulness of school higher than the other two groups (see Table 2).

Neither duration of the work-based period nor sequencing were found to be significant predictors of ratings of how well the school kept up with innovations in the field (see Table 7).

Table 7. Prediction of factor score \#5: Relevance and usefulness of school, from duration and sequencing (dummy coded).

\begin{tabular}{lcccccc}
\hline \multirow{2}{*}{ Effect } & \multirow{2}{*}{ Estimate } & \multirow{2}{*}{ SE } & $\boldsymbol{\beta}$ & \multicolumn{2}{c}{$\mathbf{9 5 \%}$ CI } & \multirow{2}{*}{$\boldsymbol{p}$} \\
\cline { 5 - 6 } & & & & $\mathbf{L L}$ & $\mathbf{U L}$ & \\
\hline Duration of workplace learning period & 0.002 & 0.001 & 0.075 & 0.000 & 0.003 & 0.084 \\
Sequencing: School-Workplace & -0.049 & 0.078 & -0.029 & -0.202 & 0.105 & 0.532 \\
Sequencing: School-Either & -0.135 & 0.077 & -0.083 & -0.288 & 0.017 & 0.081 \\
Sequencing: Either-School & -0.239 & 0.14 & -0.075 & -0.515 & 0.036 & 0.088 \\
\hline
\end{tabular}

Note. $N=587 . \mathrm{CI}=$ confidence interval; $\mathrm{LL}=$ lower limit; $\mathrm{UL}=$ upper limit. 


\section{Discussion}

This study focused on how journeymen, workplace trainers, and vocational teachers at upper secondary schools viewed the integration between learning at school and at work in the certified trades in Iceland, and how these views might be influenced by the duration of work-based learning and the sequencing of school- and work-based learning.

The first research question concerned the participants' view on the various facets of integrating learning in a dual system. The results revealed five different factors: (1) Quality and usefulness of work-based learning, (2) school keeping up with innovations in the trade, (3) program coherence and collaboration, (4) communication and information flow, and (5) relevance and usefulness of school-based learning. The literature on integrating learning in the dual system has emphasized the importance of both collaboration between school and workplaces, and of communication between teachers and workplace trainers $[4,7,9]$, and these results support this because program coherence and collaboration was one factor and communication and information flow another. Research has shown that these factors impact learning outcomes [5] and the lack of coherence and collaboration, in addition to communication, seen in the results is therefore concerning. Additionally, the results show how features of each venue (e.g., relevance, quality, usefulness, and keeping up with innovations) play a role in integration of learning experiences and considerations of how VET programs as a whole prepare students. These factors concern how the two venues relate to each other and to the trade in general, and show how important these connections are. The results also indicate the integral role of pedagogical practices in how integration is perceived, in line with prior research [5,19], because statements describing pedagogical practices are interspersed with more general statements. Furthermore, each of the five factors can be investigated with the aim of improving the integration of the two learning venues, and the overall outcome of the dual system of VET, particularly in the case of Iceland, because the results point to a dual system that seems to consist of two parallel parts rather than a single coherent program. The findings here show a distinct lack of systematic communication or collaboration between those responsible for delivering education at each learning venue; recently graduated journeymen, in particular, did not experience the program as a coherent whole. Furthermore, it is clear that both learning venues were valued and seen as important. Taken together, these results can provide guidance for practitioners in the field. It is important that those who teach vocational studies at schools and those who guide students during workplace learning periods establish and maintain a discussion on what is taught and student progress. Optimally, the system should be set up to guarantee regular communication and collaboration, with clear assigned roles and responsibilities for assisting students in integrating learning experiences from each venue.

The second research question concerned comparison of the views of the three groups of participants on the integration of the two learning venues. The results showed interesting differences, in which teachers were more likely to have positive views of the school and trainers more likely to have positive views of work-based learning than were the other groups. This probably reflects their representation of each learning venue. Recently graduated journeymen rated program coherence and collaboration lower than did both trainers and teachers. One explanation could be that as students, the journeymen might have been unaware of the collaboration taking place and lacked the overview of the program that teachers and trainers have. Another could be that the students experienced a lack of coherence while undergoing the program, whereas teachers and trainers may be unaware of this lack of coherence because they are mostly only involved in one part of the program. Regardless of the explanation, it must be considered problematic if the students do not experience coherence and integration between school and workplace. If integration of learning experiences is based on how students frame and create meaning from their experiences at each venue [9], these results suggest that the system fails to assist them in doing so. Interestingly, trainers rated coherence and collaboration higher than did journeymen and teachers and they also generally rated communication and information flow higher. This might reflect the view seen in interviews with some trainers that they do not need to know what happens at the school or be in contact with teachers [13]. 
The third research question focused on whether duration or sequencing related to the perceived integration of learning at school and in the workplace. Interestingly, no relationship was found between duration and how participants viewed integration. This is somewhat surprising, given the large degree of variation in the duration of work-based learning in the Icelandic dual VET system, in which there is over 102 weeks' difference between the shortest and longest work-based learning period [14]. It is difficult to hypothesize on the basis of a null result, but tentatively, it might be said that the duration of the work-based learning period has a limited effect on how stakeholders perceive the integration of the two learning venues. However, this says nothing about other effects that duration of work-based learning might have, such as student outcomes or identity formation. Sequencing was only found to affect ratings of communication and information flow. The results suggest that those involved in the four trades fitting the Either-School sequencing pattern have managed to establish better communication between school and workplaces than participants in trades that begin and conclude at school (School-School). Further research is needed to investigate the cause and could produce helpful guidance for how the communication and information flow between schools and workplaces can be strengthened. In the literature on integrating learning experiences gained at school and work, it has been proposed that duration and sequencing might play a role [4,9,25-27], but the results here do not support these predictions. Given the limitations in studying these characteristics of the dual system in practice, and the considerable variation in the Icelandic system, the lack of effect is worth noting.

There are limitations to the current study that must be mentioned. The use of a self-reported measure and the low response rate of journeymen and trainers restricts the conclusions. In addition, in this study, an attempt is made to look at duration and sequencing as abstract features of the system, however, it is also important to consider that these are not necessarily independent [14], and the context of each trade is important in determining students' educational experience. Nonetheless, the results discussed here do provide information on integrating learning in a dual VET system, revealing the different facets of integration, and showing that duration and sequencing of work-based learning appear to have limited effects on perceptions of integration. In addition, if a coherent and integrated VET program is the goal, it is necessary to understand the perspectives of the participants in the system, recent students, trainers, and teachers, and how their views of these different facets of integration vary according to their standpoint.

Funding: Icelandic Ministry of Education, Sciences and Culture: MMR13060058, University of Iceland Research Fund: NA.

Conflicts of Interest: The author declares no conflict of interest. The funders had no role in the design of the study; in the collection, analyses, or interpretation of data; in the writing of the manuscript, or in the decision to publish the results.

\section{Appendix A}

Table A1. The 22 statements in the questionnaire concerning integrating learning at school and the workplace. All were answered on a 4-point Likert scale: Strongly disagree, disagree, agree, strongly agree, or does not apply (NA).

\begin{tabular}{|c|c|c|c|}
\hline Nr. & Statement & $N$ & $\begin{array}{c}\text { Excluded } \\
\text { Group }\end{array}$ \\
\hline 1 & Teachers and workplace trainers are in regular contact & 554 & \\
\hline 2 & Workplace trainers know what students do at school & 464 & Teachers \\
\hline 3 & Teachers know what students do during the work-based learning & 403 & Trainers \\
\hline 4 & Teachers and trainers meet regularly to discuss students' progress & 273 & Journeymen \\
\hline 5 & At school we discuss situations that might come up at the workplace & 403 & Trainers \\
\hline 6 & During work-based learning students apply knowledge acquired at school & 459 & Teachers \\
\hline 7 & Students work on school assignments at the workplace & 565 & \\
\hline 8 & The periods at school and work create a coherent whole & 565 & \\
\hline
\end{tabular}


Table A1. Cont.

\begin{tabular}{|c|c|c|c|}
\hline Nr. & Statement & $N$ & $\begin{array}{c}\text { Excluded } \\
\text { Group }\end{array}$ \\
\hline 9 & There is good collaboration between the school and the workplace & 563 & \\
\hline 10 & There is a clear connection between what is taught at school and tasks at the workplace & 563 & \\
\hline 11 & At the school/workplace we prepare the students specifically for the workplace/school & 281 & Journeymen \\
\hline 12 & Innovative changes in the trade are integrated into the school curriculum & 546 & \\
\hline 13 & The school is up-to-date on developments in the trade & 542 & \\
\hline 14 & Students visit workplaces as part of the school program & 377 & Trainers \\
\hline 15 & There should be more emphasis on the work-based learning at school & 539 & \\
\hline 16 & The school prepares students well for the journeyman's exam & 541 & \\
\hline 17 & Assignments at school are clearly related to the work done in the trade & 538 & \\
\hline 18 & The training received at the workplace serves students well at school & 499 & \\
\hline 19 & The work-based learning prepares students well for the journeyman's exam & 499 & \\
\hline 20 & The work-based learning serves students well after the journeyman's exam & 497 & \\
\hline 21 & The workplace is up-to-date on developments in the trade & 496 & \\
\hline 22 & The workplace offers experiences in most relevant parts of the job & 494 & \\
\hline
\end{tabular}

\section{References}

1. Billett, S. Vocational learning: Contributions of workplaces and educational institutions. In International Handbook of Education for the Changing World of Work; Maclean, R., Wilson, D., Eds.; Springer: Berlin/Heidelberg, Germany, 2009; Volume 4, pp. 1711-1723.

2. Griffiths, T.; Guile, D. A connective model of learning: The implications for work process knowledge. Eur. Educ. Res. J. 2003, 2, 56-73. [CrossRef]

3. Lindberg, V. Vocational knowing and the content in vocational education. Int. J. Train. Res. 2003, 1, 40-61. [CrossRef]

4. Schaap, H.; Baartman, L.; de Bruijn, E. Students' Learning Processes during School-Based Learning and Workplace Learning in Vocational Education: A Review. Vocat. Learn. 2012, 5, 99-117. [CrossRef]

5. Virtanen, A.; Tynjälä, P.; Eteläpelto, A. Factors promoting vocational students learning at work: Study on student experiences. J. Educ. Work 2014, 27, 43-70. [CrossRef]

6. Kilbrink, N.; Bjurulf, V. Transfer of knowledge in technical vocational education: A narrative study in Swedish upper secondary school. Int. J. Technol. Des. Educ. 2013, 23, 519-535. [CrossRef]

7. Choy, S.; Wärvik, G.-B.; Lindberg, V. Considerations for the integration of students' experiences. In Integration of Vocational Education and Training Experiences; Choy, S., Wärvik, G.-B., Lindberg, V., Eds.; Springer: Singapore, 2018; pp. 345-366.

8. INAP Commission. An architecture for modern apprenticeships: Standards for structure, organisation and governance. In The Architecture of Innovative Apprenticeship; Deitmer, L., Hauschildt, U., Rauner, F., Zelloth, H., Eds.; Springer: New York, NY, USA, 2013; pp. 1-24.

9. Billett, S. Integrating learning experiences across tertiary education and practice settings: A socio-personal account. Educ. Res. Rev. 2014, 12,1-13. [CrossRef]

10. Mulder, R.H.; Messmann, G.; König, C. Vocational education and training: Researching the relationship between school and work. Eur. J. Educ. 2015. [CrossRef]

11. Billett, S.; Wärvik, G.-B.; Choy, S. Concepts, purposes and practices of integration across national curriculum. In Integration of Vocational Education and Training Experiences; Choy, S., Wärvik, G.-B., Lindberg, V., Eds.; Springer: Singapore, 2018; pp. 327-344.

12. Tynjälä, P. Toward a 3-P model of workplace learning: A literature review. Vocat. Learn. 2013, 6, 11-36. [CrossRef]

13. Eiriksdottir, E. Nám í skóla og á vinnustað: Viðhorf og reynsla sveina, kennara og meistara af tvískiptu kerfi löggiltra iðngreina. Tímarit Um Uppeldi Og Menntun 2017, 26, 43-64. [CrossRef]

14. Eiriksdottir, E. Variations in implementing the dual VET system: Perspectives of studnets, teachers, and trainers in the certified trades in Iceland. In Integration of Vocational Education and Training Experiences; Choy, S., Wärvik, G.-B., Lindberg, V., Eds.; Springer: Singapore, 2018; pp. 145-164.

15. Cedefop. Terminology of European Education and Training Policy; Publications Office of the European Union: Luxembourg, 2014. 
16. Grollmann, P. Varieties of "duality": Work-based learning and vocational education in international comparative research. In Integration of Vocational Education and Training Experiences; Choy, S., Wärvik, G.-B., Lindberg, V., Eds.; Springer: Singapore, 2018; pp. 63-84.

17. Baartman, L.K.J.; de Bruijn, E. Integrating knowledge, skills and attitudes: Conceptualising learning processes towards vocational competence. Educ. Res. Rev. 2011, 6, 125-134. [CrossRef]

18. Baartman, L.K.J.; Kilbrink, N.; de Bruijn, E. VET students' integration of knowledge engaged with in school-based and workplace-based learning environments in The Netherlands. J. Educ. Work 2018, 31, 204-217. [CrossRef]

19. Tynjälä, P. Perspectives into learning at the workplace. Educ. Res. Rev. 2008, 3, 130-154. [CrossRef]

20. Guile, D.; Griffiths, T. Learning through work experience. J. Educ. Work 2001, 14, 113-131. [CrossRef]

21. Sappa, V.; Aprea, C.; Vogt, B. Success factors for fostering the connection between learning in school and at the workplace: The voice of Swiss VET actors. In Integration of Vocational Education and Training Experiences; Choy, S., Wärvik, G.-B., Lindberg, V., Eds.; Springer: Singapore, 2018; pp. 303-326.

22. Virtanen, A.; Tynjälä, P.; Collin, K. Characteristics of Workplace Learning Among Finnish Vocational Students. Vocat. Learn. 2009, 2, 153. [CrossRef]

23. Akkerman, S.F.; Bakker, A. Crossing Boundaries Between School and Work During Apprenticeships. Vocat. Learn. 2012, 5, 153-173. [CrossRef]

24. Sappa, V.; Choy, S.; Aprea, C. Stakeholders' conceptions of connecting learning at different sites in two national VET systems. J. Vocat. Educ. Train. 2016, 68, 283-301. [CrossRef]

25. Billett, S. Student readiness and the integration of experiences in practice and education settings. In Integration of Vocational Education and Training Experiences; Choy, S., Wärvik, G.-B., Lindberg, V., Eds.; Springer: Singapore, 2018; pp. 19-40.

26. Winch, C.; Clare, L. "Front-loaded" vocational education versus lifelong learning: A critique of current UK government policy. Oxf. Rev. Educ. 2003, 29, 239-252. [CrossRef]

27. Evans, K.; Guile, D.; Harris, J. Rethinking work-based learning: For education professionals and professionals. In The Sage Handbook of Workplace Learning; Malloch, M., Cairns, L., Evans, K., O'Connor, B.N., Eds.; Sage: Los Angeles, CA, USA, 2011; pp. 149-162.

28. Ministry of Education, Science and Culture. Samantekt úr Education at a Glance 2018: Skýrsla OECD um Menntatölfræði (Summary on Iceland from Education at a Glance); Ministry of Education, Science and Culture: Reykjavík, Iceland, 2018.

29. Ministry of Education, Science and Culture. OECD Review: Skills Beyond School-National Background Report for Iceland; Ministry of Education, Science and Culture: Reykjavik, Iceland, 2013.

30. Reglugerð um Löggiltar Iðngreinar (Regulation on Certified Trades). In No. 940; 1999. Available online: https://www.reglugerd.is/reglugerdir/eftir-raduneytum/idnadarraduneyti/nr/2736 (accessed on 30 October 2020).

31. Cedefop. Apprenticeship Schemes in European Countries; Publications Office of the European Union: Luxembourg, 2018.

32. Field, A. Discovering Statistics Using IBM SPSS Statistics; Sage: Los Angeles, CA, USA, 2013.

33. DiStefano, C.; Min, Z.; Mîndrilã, D. Unerstanding and using factor scores: Considerations for the applied researcher. Pract. Assess. Res. Eval. 2009, 14. [CrossRef]

Publisher's Note: MDPI stays neutral with regard to jurisdictional claims in published maps and institutional affiliations.

(C) 2020 by the author. Licensee MDPI, Basel, Switzerland. This article is an open access article distributed under the terms and conditions of the Creative Commons Attribution (CC BY) license (http://creativecommons.org/licenses/by/4.0/). 